\title{
Hypertensive heart disease versus hypertrophic cardiomyopathy: multi-parametric CMR predictors beyond end-diastolic wall thickness $\geq 15 \mathrm{~mm}$
}

\author{
Jonathan C Rodrigues ${ }^{*}$, Stephen Rohan², Amardeep Ghosh Dastidar', Amy E Burchell ${ }^{3}$, Laura E Ratcliffe ${ }^{3}$, \\ Emma C Hart ${ }^{3}$, Julian F Paton ${ }^{3}$, Mark Hamilton' ${ }^{1}$, Angus K Nightingale ${ }^{3}$, Nathan E Manghat ${ }^{1}$ \\ From 19th Annual SCMR Scientific Sessions \\ Los Angeles, CA, USA. 27-30 January 2016
}

\section{Background}

Both American and European guidelines for the management of hypertrophic cardiomyopathy ( $\mathrm{HCM}$ ) advise that HCM be considered when LV end-diastolic wall thickness (EDWT) $\geq 15 \mathrm{~mm}$ in $\geq 1$ myocardial segment. Hypertensive heart disease (HHD) is a common cause of left ventricular hypertrophy $(\mathrm{LVH})$. Distinguishing between HHD and HCM is a frequent clinical conundrum. We aimed to identify predictors of HHD versus HCM with EDWT $\geq 15 \mathrm{~mm}$, using multi-parametric cardiac magnetic resonance (CMR) including pixel-wise myocardial segmental EDWT analysis.

\section{Methods}

HCM with EDWT $\geq 15 \mathrm{~mm}$ were identified from 2481 consecutive clinical CMRs between 2014-15. Those without a diagnosis of HCM $(n=2428)$, with concomitant hypertension $(n=21)$, apical HCM only $(n=2)$ and severe renal impairment $(\mathrm{n}=1)$ were excluded. Analysis of 464 myocardial segments from 29 HCM subjects was performed.

HHD with EDWT $\geq 15 \mathrm{~mm}$ were identified from a separate prospectively maintained tertiary hypertension clinic database of 150 consecutive referrals. Hypertensive subjects with EDWT $\leq 15 \mathrm{~mm}(\mathrm{n}=102)$, concomitant cardiac pathology $(n=17)$ and CMR contraindications $(n=4)$ were excluded. Analysis of 432 segments from 27 HHD subjects were performed.

EDWT was measured by pixel-wise analysis. Segmental distribution of EDWT $\geq 15 \mathrm{~mm}$, mean segmental thickness, segmental distribution of late gadolinium

${ }^{1}$ CMR Unit, NIHR Cardiovascular Biomedical Research Unit, Bristol Heart Institute, Bristol, United Kingdom

Full list of author information is available at the end of the article enhancement (LGE) were recorded. EDWT asymmetry, defined as $>1.5$-fold the opposing segment, was documented. The prevalence of other potential discriminators including systolic anterior motion of the mitral valve (SAM) and aorto-septal angulation (AoSA) were measured.

Unpaired $\mathrm{T}$ tests and multivariate logistic regression analysis was performed. Significance was set at twotailed $\mathrm{p}<0.05$.

\section{Results}

HHD and HCM cohorts were matched in age (HHD: 57 \pm 13 vs HCM: $62 \pm 10$ years, $\mathrm{P}=0.20$ ) and gender (74 vs $59 \%$ male, $\mathrm{P}=0.28)$. HHD had significantly increased indexed LV mass $(110 \pm 27$ vs $91 \pm 31 \mathrm{~g} / \mathrm{m} 2, \mathrm{p}<0.05)$ and mass : volume ratio $(1.44 \pm 0.28$ vs $1.29 \pm 0.33$, p < $0.05)$ compared to HCM but no significant difference in indexed LV volumes. There were no significant differences in the anatomical site or magnitude of maximal EDWT between HHD and HCM (Figure 1. A-D). The prevalence of LGE was significantly higher in HCM than HHD (Figure 1. E-F). Elevated indexed LVM, absence of SAM and absence of midwall LGE were significant predictors of HHD in the multivariate logistic regression model, but LV asymmetry was not (Table 1).

\section{Conclusions}

There is a significant morphological overlap (location and magnitude of hypertrophy) between HHD and HCM. Both conventional EDWT $\geq 15 \mathrm{~mm}$ cut-off and LV asymmetry are poor discriminators. Elevated indexed LVM, absence of SAM and absence of midwall LGE are significant predictors of HHD. Tissue characterisation with LGE is unique to CMR and our findings support 


\section{Percentage segments with EDWT $\geq 15 \mathrm{~mm}$}

1. A) Hypertensive Heart Disease

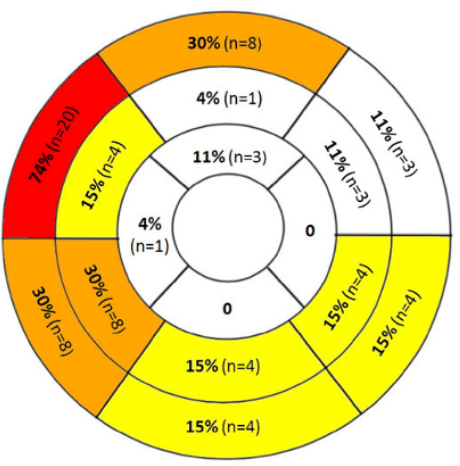

\section{Mean segmental EDWT}

1. B) Hypertrophic cardiomyopathy

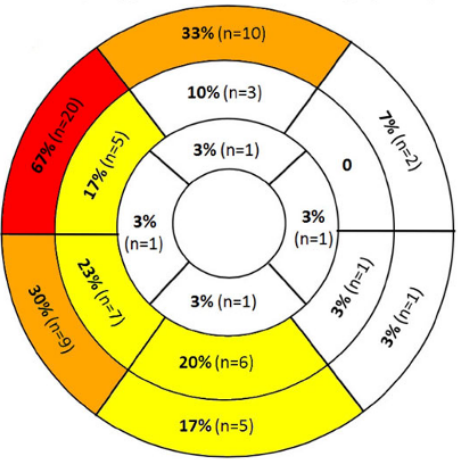

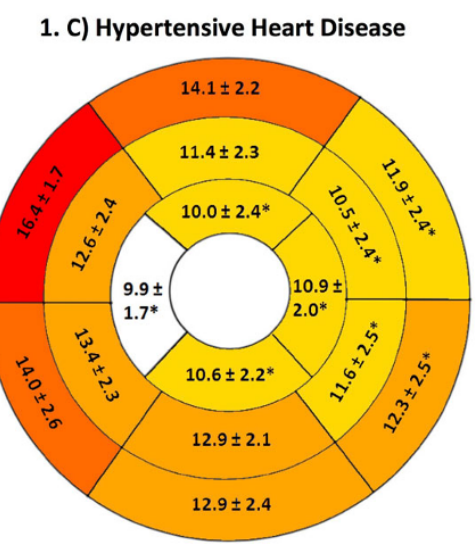

1. D) Hypertrophic cardiomyopathy

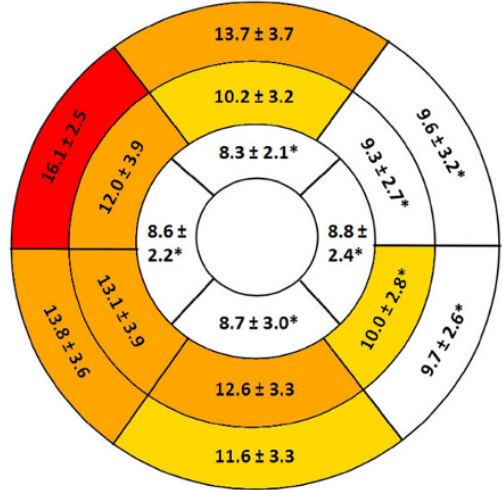

Segmental LGE distribution

1. E) Hypertensive Heart Disease

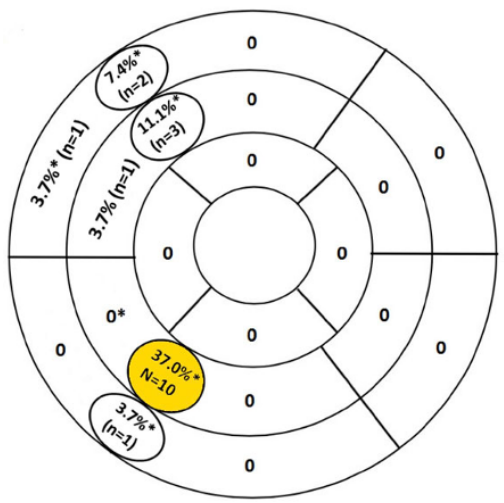

1. F) Hypertrophic cardiomyopathy

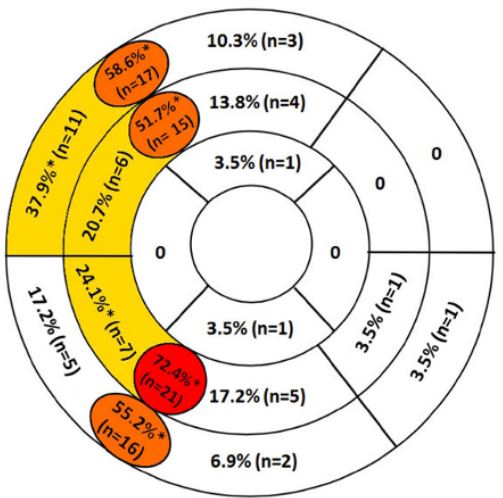


Table 1 Univariate and multivariate logistic regression analysis to determine predictors of hypertensive heart disease

\begin{tabular}{|c|c|c|c|c|}
\hline & Univariate analysis & & Multivariate analysi & \\
\hline & OR $(95 \% \mathrm{Cl})$ & $P$ value & OR $(95 \%$ Cl) & $P$ value \\
\hline Age (years) & $0.99(0.93-1.02)$ & $=0.20$ & $\ldots$ & $\ldots$ \\
\hline Male gender & $2.02(0.65-6.27)$ & $=0.23$ & $\ldots$ & $\ldots$ \\
\hline Indexed LVM (g/m2) & $1.02(1.00-1.04)$ & $<0.05^{*}$ & $1.05(1.01-1.09)$ & $<0.05^{*}$ \\
\hline Mass : Volume ratio $(\mathrm{g} / \mathrm{ml})$ & $5.03(0.81-31.44)$ & $=0.08$ & $\ldots$ & $\ldots$ \\
\hline EDWT Asymmetry & $0.08(0.02-0.33)$ & $<0.0001^{*}$ & $1.74(0.11-28.96)$ & $=0.70$ \\
\hline SAM & $0.05(0.01-0.21)$ & $<0.0001^{*}$ & $0.01(0.00-0.25)$ & $<0.005^{*}$ \\
\hline Aortoseptal angle (degrees) & $1.02(0.97-1.08)$ & $=0.49$ & $\ldots$ & $\ldots$ \\
\hline Midwall LGE & $0.04(0.01-0.15)$ & $<0.0001^{*}$ & $0.01(0.00-0.18)$ & $<0.005^{*}$ \\
\hline
\end{tabular}

$\mathrm{OR}=$ odds ratio, $\mathrm{Cl}=$ confidence interval, $\mathrm{LVM}=$ left ventricular mass, EDWT = end-diastolic wall thickness, SAM = systolic anterior motion of the mitral valve, LGE = late gadolinium enhancement.

its extended use in cases of suspected HCM, particularly where there is concomitant hypertension.

\section{Authors' details}

${ }^{1}$ CMR Unit, NIHR Cardiovascular Biomedical Research Unit, Bristol Heart Institute, Bristol, United Kingdom. '2Faculty of Medicine, University of Bristol, Bristol, United Kingdom. ${ }^{3}$ Cardionomics Research Group, Bristol Heart Institute, Bristol, United Kingdom.

Published: 27 January 2016

doi:10.1186/1532-429X-18-S1-P264

Cite this article as: Rodrigues et al: Hypertensive heart disease versus hypertrophic cardiomyopathy: multi-parametric CMR predictors beyond end-diastolic wall thickness $\geq 15 \mathrm{~mm}$. Journal of Cardiovascular Magnetic Resonance 2016 18(Suppl 1):P264.

Submit your next manuscript to BioMed Central and take full advantage of:

- Convenient online submission

- Thorough peer review

- No space constraints or color figure charges

- Immediate publication on acceptance

- Inclusion in PubMed, CAS, Scopus and Google Scholar

- Research which is freely available for redistribution

Submit your manuscript at www.biomedcentral.com/submit
C Biomed Central 